\title{
RETURN TO WORK AFTER SPINAL STENOSIS SURGERY AND THE PATIENT'S QUALITY OF LIFE
}

\section{ALEKSANDRA TRUSZCZYŃSKA ${ }^{1,2}$, KAZIMIERZ RĄPAŁA ${ }^{1,4}$, OLAF TRUSZCZYŃSKI ${ }^{3}$, ADAM TARNOWSKI ${ }^{3}$, and STANISŁAW ŁUKAWSKI ${ }^{1}$}

\author{
${ }^{1}$ Prof. A. Gruca Independent Public Research Hospital, Otwock, Poland \\ Department of Orthopaedic Surgery, Centre of Postgraduate Medical Education \\ ${ }^{2}$ Józef Piłsudski University of Physical Education, Faculty of Physical Education and Sport, Biała Podlaska, Poland \\ ${ }^{3}$ Military Institute of Aviation Medicine, Warszawa, Poland \\ ${ }^{4}$ University of Social Science, Warszawa, Poland \\ Physiotherapy Department
}

\begin{abstract}
Introduction: The return to work of patients who undergo spinal surgery poses important medical and social challenge. Objectives: 1) To establish whether patients who undergo spinal stenosis surgery later return to work. 2) To establish the patient's attitude towards employment. 3) To assess the quality of life of the patients and its influence on their attitude to work. Materials and Methods: The study population consisted of 58 patients aged from 21 to 80 years (the mean age was $52.33 \pm 14.12$ ). There were 29 women (50\%) and 29 men (50\%) in the group. The patients' quality of life was measured by the use of the WHOQOL-BREF instrument. Individual interviews were conducted 3 to 8 months (a mean of 5.72 months \pm 1.6 ) after the surgery. Results: 1) Although 13 patients $(22.3 \%$ ) returned to work, $44(75.9 \%)$ did not, these being manual workers of vocational secondary education. 2) Almost half of the patients (27 patients, i.e. $44 \%)$ intend to apply for disability pension, 16 patients $(27.6 \%)$ consider themselves unfit to work, 22 patients (37.9\%) do not feel like working again. 3) The quality of life of the patients decreased. Domain scores for the WHOQOL-BREF are transformed to a 0-100 scale. The mean physical health amounted to $60.67( \pm 16.31)$, the mean psychological health was $58.78( \pm 16.01)$, while the mean social relations with family and friends were $59.91( \pm 20.69)$, and the mean environment $59.62( \pm 12.48)$. Conclusions: 1$)$ A total of $75 \%$ of the patients operated for lumbar spinal stenosis do not return to their preoperative work. Difficulties in returning to work and decreased quality of life are associated with female sex, lower-level education, hard physical work and low income. 2) Physical health, psychological health, social relations and environment decreased to the mean of approximately 60.3) The quality of life of the patients who did return to work was similar to that of healthy people.
\end{abstract}

Key words:

Return to work, Spinal stenosis, Quality of life, Spine surgery

\section{INTRODUCTION}

Lumbar spinal stenosis is an abnormal narrowing of the spinal canal and the intervertebral foramina. Stenosis may be caused by nucleus pulposus hernia, degenerative disorders of intervertebral joints, a degenerative spondylolysthesis, a thickening of flavum ligaments or a congenital narrowing. Stenosis manifests itself in low back pain radiating to lower limbs and neurogenic claudication, sometimes considerably limiting gait possibilities.

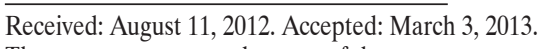

The paper was prepared as part of the statutory research programme No. DS.168 of Józef Piłsudski University of Physical Education, Faculty of Physical Education and Sport in Biała Podlaska.

Corresponding author: A. Truszczyńska, Józef Piłsudski University of Physical Education, Faculty of Rehabilitation, Marymoncka 34, 01-968 Warszawa, Poland (e-mail: aleksandra.rapala@wp.pl). 
Patients who undergo spine surgery due to lumbar stenosis find it difficult to return to work, and many attempt to claim a disability pension. Several factors influence the decision but the most important are: remaining pain, low education, heavy physical work, lack of satisfaction with previous work and psychological stress caused by the surgery. This difficulty is increasingly apparent in Poland. There is no rational justification for not returning to work within a relatively short time span after the surgery in the case of patients who suffer from low back pain associated with their source of employment. Encouraging them to return to work quickly prevents the acquisition of behaviours typical of patients on long-term sick leave: depression, apathy and anxiety. Patients with back pain should attempt to return to work despite some remaining pain, as sometimes pain does not fully subside until the patient returns to full activity. Hence, if they do not suffer from serious spinal disorders such as spine injuries, spinal infections, cancer, osteoporosis related fractures or progressive neurological symptoms, the patients should be encouraged and motivated to stay active.

\section{OBJECTIVES OF THE STUDY}

Objectives of the study:

1. To establish whether the patients who undergo spinal stenosis surgery do not return to work.

2. To establish the patients' attitude towards employment.

3. To assess the patients' quality of life and its influence on their attitude to work.

\section{MATERIALS AND METHODS}

The study population consisted of 58 patients who were surgically treated for lumbar stenosis at the Department of Orthopaedic Surgery of the Centre of Postgraduate Medical Education in Otwock between September 2011 and March 2012. The group included 29 women (50\%) and 29 men $(50 \%)$.

The patients were aged from 21 to 80 years (the mean age was $52.33 \pm 14.12$ ). They were interviewed by a pollster who was unaware of the aim of the study. The individual interviews were conducted between 3 and 8 months (the mean of 5.72 month \pm 1.6 ) after the surgery.

The exclusion criteria were: the presence of additional spinal disorders and lack of patient's consent to participate in the study.

\section{Statistical analysis}

The Spss v.18 statistics package was used. In cases where the independent (explanatory) variables were dichotomous, the Student's t-test was applied for independent trials, while the equality of variance was checked by the use of Levene's test. In the cases of independent variables measured on the least rank level, correlation was established using the Kendall rank correlation coefficient. In both cases, two-sided statistical significance was the basis.

\section{RESULTS}

Before the surgery, 34 patients $(58.4 \%)$ performed physical work, 2 patients $(3.4 \%)$ had intellectual work, 5 patients $(8.6 \%)$ were drawing disability pensions, 16 patients $(27.6 \%)$ were retired and one patient was unemployed. The job of 39 patients $(67.2 \%)$ involved lifting heavy weights, and the job of 19 patients $(32.8 \%)$ involved sitting for a long time. 36 patients $(62.1 \%)$ had only primary education or vocational secondary education, 18 patients $(31 \%)$ had secondary education, and only 4 patients $(7.31 \%)$ were university graduates. 44 patients $(75.9 \%)$ did not return to their preoperative work, and only 13 patients $(22.3 \%)$ returned to their work within 6 weeks to 6 months after the surgery. Only 1 person returned to work in less than 6 weeks after the surgery. 
Almost a half of the patients (27 people), i.e. $44 \%$, intend to apply for a disability pension. Sixteen patients (27.6\%) consider themselves unfit to work, while 22 patients (37.9\%) do not feel like working again.

The quality of life of the studied patient population was measured with the WHOQOL-BREF instrument. The World Health Organization defines quality of life as "an individual's perception of their position in life in the context of the culture and the value systems in which they live and in relation to their goals, expectations, standards and concerns" and goes on to state that "quality of life refers to a subjective evaluation which is embedded in cultural, social and environmental contexts" [1]. The WHOQOL-BREF instrument measures aspects of physical health, psychological health, social relations and environment.

The physical health assessment involves activities of daily life, dependence on medical substances and medical aids, energy and fatigue, mobility, pain and discomfort, sleep and rest, work capacity. Psychological health comprises bodily image and appearance, negative feelings, positive feelings, self-esteem, religion, memory and concentration. Social relationships involve personal relationships, social support and sexual activity. Finally, environment comprises financial resources, freedom, physical safety and security, while the health care section comprises accessibility and quality, home environment, participation in and opportunities for recreational and leisure activities, pollution of the physical environment and accessibility of transport. WHOQOL-BREF domain scores are calculated by taking the mean of all items included in each domain and multiplying by four. These scores are then transformed to a 0-100 scale. In comparison to the established norms, the mean average health of the studied patient population was $60.67( \pm 16.31)$, the mean psychological health was $58.7( \pm 16.01)$, social relations - relationships with family and friends $-59.91( \pm 20.69)$, and the mean environment was $59.62( \pm 12.48)$.
The following statistically significant correlations were found:

1. There was a negative correlation between the patient's age and patient's social relations: the older the patients, the worse their relationships with family and friends $(-0.485)(p=0.000)$.

2. There was a negative correlation between patient's age and environment: the older the patients were, the worse they assessed the impact of environment on their health $\left(-0.280^{* *}\right)(\mathrm{p}=0.000)$.

3. A statistically significant difference in assessment of environment was noted: the better the patients were educated, the higher they ranked their environment $(\mathrm{p}=0.011)$.

4. No statistically significant difference was found with regard to psychological health, but there was a strong positive tendency: the better the patient was educated, the better they assessed their psychological health $(\mathrm{p}=0.53)$.

5. The quality of life of the patients who have returned to work is significantly higher than the quality of life of those who did not. The mean physical health score was 57.5 for the patients who intend to apply for disability pension, and 72.69 for the patients who returned to work. The mean psychological health scores were 55.43 and 70.31 respectively, the mean for social relations were 55.41 and 75.46 respectively, and the mean environment ratings were 56.41 and 70.23 respectively. The quality of life of the patients who had returned to work was similar to the quality of life of healthy people.

\section{DISCUSSION}

The issue of the return to work of patients who undergo spinal surgery has been addressed in numerous studies. According to a Belgian study [2], percentages of the patients who have returned to work are as follows: $14.4 \%$ of the patients who had discectomy, $22.7 \%$ of the patients 
who had anterolateral stabilization, $26.1 \%$ of the patients who had posterior stabilization and $30.6 \%$ of the patients who had both discectomy and stabilization. Du Bois et al. [3] suggest that patients suffering from pain in the lumbar spine may develop behaviour typical of patients on longterm sick leave.

In a randomised study, Jensen et al. [4] determine the percentage of patients suffering from back pain who returned to work after a long-term sick leave of 3 to 16 weeks. Two studied groups received different treatment methods. In group A, the treatment involved medical examination by a surgeon and a physiotherapist; and the patient was advised how to take good care of his spine. In group B, a multidisciplinary programme was applied. The programme involved, among others, consultation with a job advisor. The difference in patient return to work was not significant, and the results were $71 \%$ and $76 \%$ respectively. Nguyen et al. [5] note that only $26 \%$ of the patients who had surgery of lumbar spine returned to work, compared with $67 \%$ of the patients from a control group who had received conservative treatment.

In a German study, Ziegler et al. [6] note a high percentage of patients who returned to work. They studied 305 patients treated surgically for spinal disc disorder and considered the psychological and socio-economic burdens placed on the patients. Three months after the operation, $84.5 \%$ of the patients were able to return to work. According to Ziegler et al. [6], the factors that cause working activity disorders are lower-level education, unemployment, poor subjective job opportunities, long-term in-hospital treatment, prior spinal surgery, pain in other segments of the spine, as well as high intensity of subjectively-felt pain. According to the authors, the high-risk patients should receive a therapy that would involve medical, social, pain relief and psychological support.

In our study, numerous factors were found which jeopardized return to work; most significantly: lower-level education, unemployment and poor quality of life.
In an American study, Cole et al. [7] attempted to estimate the postoperative costs of surgical treatment. Pain and disability after lumbar fusion surgery was found to account for more than $\$ 20$ billion spent on health care and an estimated $\$ 28$ billion in lost wages annually. The estimated cost of spinal pain treatment ranges from $\$ 20$ to $\$ 50$ billion a year [8]. Lumbar spine pain contributes to the loss of 159 million working days a year, and the estimated loss in production in the US amounts to $\$ 28$ billion [9]. It has been calculated that the cost of surgery in the US has increased by $500 \%$ and that it constitutes approximately $40 \%$ of all expenses on pain treatment [10]. There are no similar studies in Poland. Spinal pain treatment in an outpatient clinic should involve reduction of bed rest to the minimum (1-2 days). This should be achieved through applying physiotherapy, hot and/ or cold compresses, anti-inflammatory and painkilling medicines. Surgical treatment should be offered if the McKenzie test reveals peripheralization of pain, if pain persists despite correct physiotherapy, or in the case of progressive neurological disorders. Patients whose disorders stem from psychological or work-related psychosocial factors should be referred to a multidisciplinary rehabilitation programme in order to prevent long-term disability [11].

From a psychological perspective, the quality of life focuses on emotional and mental well-being. This well-being embraces life changes, both in the present and in the past. The assessment involves a person's reactions to difficulties, their mood, and value judgements on their life in general [12].

The abbreviated version of the World Health Organization Quality of Life Instrument (WHOQOL-BREF) aims at measuring the quality of life of both the ill and the healthy. It contains 26 questions and has been developed on the basis of the full version of WHOQOL-100, which contains 100 questions. Establishing certain standards was one of the important objectives while developing the 
WHOQOL-BREF instrument. The points scored reflect an individual's quality of life assessment; the more points scored, the better the quality of life.

The reliability of the Polish version of the WHOQOLBREF Instrument has been tested with Cronbach's $\alpha$ coefficient, the results being as follows: 0.81 for the Physical health domain, 0.78 for the Psychological health domain, 0.69 for the Social relationships domain, 0.77 for the Environment domain, and 0.90 for the instrument as a whole [13,14]. According to an Australian study, the general norms for the WHOQOL-Bref domains are as follows: $73.5( \pm 8.1)$ for Physical health, $70.6( \pm 14.0)$ for Psychological health, $71.5( \pm 18.2)$ for Social relationships and $75.1( \pm 13.0)$ for the Environment domain [15].

In the present study, the patients who had spinal surgery scored significantly low on the Quality of Life instrument. It is notable that physical health scored best, i.e. 60.67 , and psychological health scored worst, i.e. 58.78. It seems that the decline in psychological health results from the limited knowledge of the patients concerning the surgical procedure and unrealistic expectations regarding postoperative activity. The study has to consider the sensitive matter of evaluating possibly fake physical and psychological symptoms aimed at fraudulently obtaining a disability pension.

Wadell et al. [16] believe that it is not necessary to postpone return to work until pain fully subsides [16]. It is believed that return to work does not increase the risk of further damage to the spine, in spite of some chronic pain and disability [17]. If some time off work is necessary, the period should be short. Several examples of patients returning to work despite various disorders have been discussed in a guide published by Work-Loss Data Institute [18].

Patients who suffer from spinal canal stenosis should modify their work. The modifications should concern reduction of time spent sitting, standing and walking, avoiding lifting heavy weights and driving a car. The time span of these modifications is shorter for intellectual workers, i.e. 2 weeks, and longer for physical workers, i.e. 2 to 4 weeks.

Those patients who find it difficult to return to work even 4 to 12 weeks after the surgery may benefit from interdisciplinary rehabilitation programmes [17]. The programmes should include a scheme of physical activities that improve the patient's physical fitness. The programmes should also consist of occupational and psychosocial rehabilitation and the correct form of pharmacotherapy. The teams that run them should consist of a physician, a physiotherapist and a psychologist [19].

Most of our data is similar to the data discussed by Anglophone writers. Szpalski et al. [20] conclude that lowergrade education, low income and being of female sex all predispose the patients to surgical treatment. Clauw et al. [21] note that when individuals derive benefits when experiencing pain, the pain they experience is greater.

Giesecke et al. [22,23] claim that chronic pain has its fossilized source in the central nervous system. Studies concerning return to work and the quality of life need to consider whether surgical treatment was necessary in a particular case. Scientific literature has presented numerous methods of surgical treatment which may be more extensive than the disorder itself. Many studies present insufficient information regarding the application of conservative treatment before resorting to surgical treatment; it is unclear whether conservative treatment utilising the McKenzie method had been applied by qualified therapists. A thorough diagnostic work-up known as MDT, mechanical diagnosis and therapy, allows the pain source to be established, as well as the effect of centralization, a prognostically positive symptom in which pain moves sequentially back from the limb to the spine. Brennan et al. [24] found centralization and directional preference, i.e. the direction of movement which leads to centralization, to occur in $70 \%$ of the patients who suffered from acute pain and in $50 \%$ of the patients who suffered from chronic pain. The patients in whom 
centralization and directional preference does not occur should be referred to surgical treatment [25]. Every back pain patient needs access to inexpensive and informative MDT work-up. Another study notes that centralization was observed in 32 to $50 \%$ of the patients referred to surgical treatment [26]. The MDT method provides the patients with knowledge on how to take care of their own spine. Therefore, one should remain critical of expensive surgical procedures that have not been proved effective in long-term follow-up studies. It would seem justified to review the extensive surgical budgets and widely implement the well-researched MDT method. To conclude, it can be said that a decreased quality of life is not necessarily related to the surgical treatment itself. The risk factors that should be taken into account are also female sex, lower-level education, low income, hard physical work and unemployment.

Quality of life is a very individual issue and is closely connected with human aspirations. It is possible that a low quality of life is not troubling for poorly socialised people, and an illness, or even a disability, can serve as a secondary justification of social withdrawal. Future research should focus on the social factors in medical field causing social and occupational retrieval.

\section{CONCLUSION}

1. In total, $75 \%$ of the patients operated for lumbar spinal stenosis do not intend to return and do not return to their preoperative work. Difficulties in returning to work and decreased quality of life are associated with female sex, lower-level education, hard physical work and low income.

2. The patients after surgery who did not return to work had physical, psychological, social relations and environment health decreased to the mean of approximately 60 .

3. The quality of life of the patients who return to work was similar to that of healthy people.

\section{REFERENCES}

1. Bowling A. Measuring disease. A review of disease-specific quality of life measurement scales. Buckingham: Open University Press; 2001.

2. Du Bois M, Szpalski M, Donceel P. A decade's experience in lumbar spine surgery in Belgium: sickness fund beneficiaries, 2000-2009. Eur Spine J 2012;3:2693-703.

3. Du Bois MG, Donceel P. Guiding low back claimants to work a randomized controlled trial. Spine 2012;37(17):1425-31.

4. Jensen C, Jensen OK, Christiansen DH, Nielsen CV. Oneyear follow-up in employees sick-listed because of low back pain: randomized clinical trial comparing multidisciplinary and brief intervention. Spine 2011;36(15):1180-9.

5. Nguyen TH, Randolph DC, Talmage J, Succop P, Travis R. Long-term outcomes of lumbar fusion among workers' compensation subjects: A historical cohort study. Spine 2011;15(4):320-31.

6. Zieger M, Luppa M, Meisel HJ, Günther L, Winkler D, Toussaint $\mathrm{R}$, et al. The impact of psychiatric comorbidity on the return to work in patients undergoing herniated disc surgery. J Occup Rehabil 2011;21(1):54-65.

7. Cole K, Kruger M, Bates D, Steil G, Zbreski M. Physical demand levels in individuals completing a sports performancebased work conditioning/hardening program after lumbar fusion. Spine J 2009;9(1):39-46.

8. Pai S, Sundaram LJ. Low back pain: An economic assessment in the United States. Orthop Clin North Am 2004;35:1-5.

9. Maetzel A, Li L. The economic burden of low back pain: A review of studies published between 1996 and 2001. Best Pract Res Clin Rheumatol 2002;16:23-30.

10. Weinstein JN, Lurie JD, Olson PR, Bronner KK, Fisher ES. United States' trends and regional variations in lumbar spine surgery: 1992-2003. Spine 2006;31(23):2707-14.

11. Nguyen TH, Randolph DC. Nonspecific low back pain and return to work. Am Fam Physician 2007;76(10):1497-502.

12. Diener E. Subjective well-being: The science of happiness and a proposal for a national index. Am Psychol 2000;55(1): $34-43$. 
13. Jaracz K, Kalfoss M, Górna K, Bączyk G. Quality of life in Polish: psychometric properties of the Polish WHOQoL-Bref. Scand J Caring Sci 2006;20:251-60.

14. Jaracz K. WHOQoL-BREF. In: Wołowicka L, editor. Quality of life in medical science. Poznań: Akademia Medyczna w Poznaniu; 2001. p. 276-80 [in Polish].

15. Hawthorne G, Herrman H, Murphy B. Interpreting the WHOQOL-Bref: preliminary population norms and effect sizes. Soc Indicat Res 2006;77:37-59.

16. Waddell G, Burton AK. Occupational health guidelines for the management of low back pain at work: evidence review. Occup Med (Lond) 2001;51:124-35.

17. Airaksinen O, Brox JI, Cedraschi C, Hildebrandt J, KlaberMoffett J, Kovacs F, et al. Chapter 4. European guidelines for the management of chronic nonspecific low back pain. Eur Spine J 2006;15(Suppl 2):S192-300.

18. Work-Loss Data Institute. Musculoskeletal system and connective tissue. In: Work-Loss Data Institute. Official Disability Guidelines. 12th ed. Encinitas, CA: Work-Loss Data Institute; 2007. p. 990-1023.

19. Meijer EM, Sluiter JK, Frings-Dresen MH. Evaluation of effective return-to-work treatment programs for sick-listed $p a$ tients with non-specific musculoskeletal complaints: A systematic review. Int Arch Occup Environ Health 2005;78:523-32.

20. Szpalski M, Nordin M, Skovron ML, Melot C, Cukier D. Health care utilization for low back pain in Belgium.
Influence of sociocultural factors and health beliefs. Spine 1995;15;20(4):431-42.

21. Clauw DJ, Williams D, Lauerman W, Dahlman M, Aslami A, Nachemson AL, et al. Pain sensitivity as a correlate of clinical status in individuals with chronic low back pain. Spine 1999;24(19):2035-41.

22. Giesecke T, Gracely RH, Grant MA, Nachemson A, Petzke F, Williams DA, et al. Evidence of augmented central pain processing in idiopathic chronic low back pain. Arthritis Rheum 2004;50(2):613-23.

23. Giesecke T, Gracely RH, Clauw DJ, Nachemson A, Dück MH, Sabatowski R, et al. Central pain processing in chronic low back pain. Evidence for reduced pain inhibition. Schmerz 2006;20(5):411-4, 416-7.

24. Brennan GP, Fritz JM, Hunter SJ, Thackeray A, Delitto A, Erhard RE. Identifying subgroups of patients with acute/subacute "nonspecific" low back pain: results of a randomized clinical trial. Spine 2006;31(6):623-31.

25. Laslett M, Aprill CN, McDonald B, Oberg B. Clinical predictors of lumbar provocation discography: A study of clinical predictors of lumbar provocation discography. Eur Spine J 2006;15(10):1473-84.

26. Donelson R, Aprill C, Medcalf R, Grant W. A prospective study of centralization of lumbar and referred pain. A predictor of symptomatic discs and anular competence. Spine 1997;15;22(10):1115-22.

This work is available in Open Access model and licensed under a Creative Commons Attribution-NonCommercial 3.0 Poland License - http://creativecommons.org/ licenses/by-nc/3.0/pl/deed.en. 